\title{
Quantum-mechanical modeling of \\ Hydroxyapatite towards bone composition
}

\section{DR. MARTA CORNO, PHD}

Università degli Studi di Torino

Presenting Author: marta.corno@unito.it

Hydroxyapatite $\left[\mathrm{HA}, \mathrm{Ca}_{10}\left(\mathrm{PO}_{4}\right)_{6}(\mathrm{OH})_{2}\right]$ is the main constituent of the inorganic phase of bones and teeth and is studied and applied as a biomaterial for tissues repairing and reconstructing. The biological HA is characterized by the presence of vacancies and defects, the most relevant being the carbonate ion substitution in the lattice (about $6 \%$ in weight). The $\mathrm{CO}_{3}{ }^{2-}$ ion can be accommodated either in place of the hydroxyl groups (type A defect) or of the phosphate group (type B) of the unit cell. The detailed knowledge of these possible HA defective structures has recently become fundamental to design improved prosthetic materials, since the carbonate incorporation can influence the adsorption processes at the mineral surface in the biological environment. Theoretical methods can be successfully applied to provide structural information and surface properties and to offer a comparison with experimental measurements.

In the present contribution, some recent results of our computational study on the role of carbonate ion in both fully and partially carbonated hydroxyapatite will be presented. Static calculations at the DFT level have been run to simulate structural, electronic and vibrational bulk properties of the A-, Band $\mathrm{AB}$-type defects. Moreover, ab initio molecular dynamics simulations have been employed to provide insights on the $\mathrm{CO}_{3}{ }^{2-}$ mobility [1,2]. Different surfaces of carbonated apatite, both plain and in interaction with water will also be presented [3].

[1] F. Peccati, M. Corno, M. Delle Piane, G. Ulian, P. Ugliengo, G. Valdrè (2014) J. Phys. Chem. C 118, 1364-1369.

[2] G. Ulian, G. Valdrè, M. Corno and P. Ugliengo (2014) Amer. Miner. 99, 117-127.

[3] F. Peccati, C. Bernocco, P. Ugliengo, M. Corno, (2018) J. Phys. Chem. C 122, 3934-3944. 